\title{
Machinery for Direct Sowing of Rice in Agricultural Conditions
}

\author{
Calixto Domínguez Vento ${ }^{1}$, Augusto Guilherme de Araújo ${ }^{2}$, Alexander Miranda Caballero ${ }^{3, *}$, \\ Guillermo Díaz López ${ }^{4}$, Amaury Rodríguez-Gonzáles ${ }^{5}$ \\ ${ }^{1}$ Agricultural Engineering Research Institute (IAgric), UCTB, Pinar del Río, Cuba. \\ ${ }^{2}$ Machinery for Conservation Agriculture, Londrina, Parana, Brazil. \\ ${ }^{3}$ National Institute of Agricultural Sciences (INCA), San José de las Lajas, Mayabeque, Cuba. \\ ${ }^{4}$ Los Palacios Base Scientific Technological Unit (UCTB-LP), belonging to the National Institute of Agricultural Sciences, Pinar \\ del Río, Cuba. \\ ${ }^{5}$ Agricultural Engineering Research Institute (IAgric), La Habana, Cuba.
}

How to cite this paper: Calixto Domínguez Vento, Augusto Guilherme de Araújo, Alexander Miranda Caballero, Guillermo Díaz López, Amaury Rodríguez-Gonzáles. (2021) Machinery for Direct Sowing of Rice in Agricultural Conditions. International Journal of Food Science and Agriculture, 5(3), 471-481. DOI: 10.26855/ijfsa.2021.09.018

Received: June 30, 2021

Accepted: July 26, 2021

Published: August 26, 2021

*Corresponding author: Alexander Miranda Caballero, National Institute of Agricultural Sciences (INCA), San José de las Lajas, Mayabeque, Cuba.

Email: alex@inca.edu.cu

\begin{abstract}
Cuban agriculture, to achieve the sustainability of agricultural systems, needs to initiate a transition process towards conservation agriculture practices; which implies a change in production systems and the technologies they use. Conservation agriculture (CA) implies a change in planting technologies and mechanized systems. Machinery specifically designed for the adaptation of components destined to sow in tilled soil and without residue on the surface is required, so that they are able to operate with crop residues or cover plants in different forms and situations. In Cuba, although the basic principles of conservation agriculture have been introduced in an experimental way with good results in some crops, there is not enough experience of the sowing machines to be used in a CA system based on the reduced mobilization of the soil, the coverage permanent surface area and crop rotation. In the following work, a review of the main changes of direct seeders for CA in rice agroecosystems is presented.
\end{abstract}

\section{Keywords}

Seeder, Zero Tillage, Crop Rotation, Rice Agroecosystems

\section{Introduction}

Rice cultivation is of great importance to contribute to world food security [1]. But rice production is one of the most aggressive to the soil and the environment. However, CA in recent decades has established itself as one of the most effective cropping systems to mitigate climate change, save water and counteract soil degradation, which is why many farmers who grow rice are switching to sowing of dry rice, with minimal soil disturbance [2-5].

However, the results obtained in rice agroecosystems in different parts of the world are contradictory and problems are usually reported with the establishment of the appropriate plant stand to achieve the yields obtained with the use of traditional tillage [3, 6-8]. But the transition from a traditional tillage system to a CA system implies a change of seeding technologies and mechanized systems [9].

For an adequate establishment of the crop, seeders are required with the capacity to: cut the residues or plants on the surface; make a furrow at the desired depth and with the least possible mobilization; depositing the seed directly in the furrow, maintaining an equidistance of distribution and uniformity in depth; and finally cover the furrow and compact the soil with adequate pressure [10-12]. As they do not require soil tillage, these equipments are called direct seeders.

Currently, there is a great diversity of direct seeders on the market, however, there are still some problems in the performance and quality of sowing of the equipment, specifically: in the operation on vegetation cover that can result in an increase in obstruction and burial of the residues in the furrow, due to failures in the cut; in the great mobilization of the 
soil in the furrow, mainly with the use of bars or chisels, which results in less coverage of the soil surface and a poor sowing quality [13] and in the control of the coverage and compaction of the soil in the sowing furrow.

To avoid these inconveniences, it is essential to adapt the seeder to the type of soil, to the management of plant cover, to the production system and to the local environmental and socio-economic conditions of each country.

In Cuba, although there have been several investigations related to CA, in practice, there is not enough experience on the sowing machines to be used and their technical requirements for a CA system. The objective of this work is to collect the information that exists on the main changes of the direct seeders for the AC in rice agroecosystems.

\section{Growth}

\subsection{Specific machinery for direct sowing.}

To carry out direct seeding in conservation agriculture based on reduced soil mobilization, seeders (direct seeders) different from those used for conventional tillage are used. The sowing equipment must be able to deposit the seed with a precision similar to that of conventional seeders, in uncultivated soil that, ideally, is covered with a large cover of crop residues. For this reason, the equipment must have specially designed cutters, openers and row covers that can penetrate the layer of residue without piling it up or pushing it into the ground, and deposit the seed in the soil at the desired depth and planting density $[9,14,15]$.

In general, no-till equipment has to be robust enough to withstand the greatest active stresses, since the soil does not move, resulting in equipment, in general, heavier than a conventional planter $[9,14,15]$.

The main functions that a direct seeder must perform are: residue management in the planting line, furrow opening, seed and fertilizer distribution, furrow covering and compaction [16].

\subsubsection{Waste management in the planting line.}

For cutting the stubble, the discs behave the best, attacking the plant debris in a vertical downward direction and cutting them, at the same time that they open a small furrow, the width of which will be determined by the shape of the disc $[14,17]$

The types of cutter disc are very varied in terms of shape and size, with smooth, grooved, grooved, corrugated and driven discs, with diameters ranging from 30 to $60 \mathrm{~cm}$ and thicknesses of 3 to $12 \mathrm{~mm}$. Flat discs with wavy edges are preferable, as they produce a more effective cutting action of the residue $[18,19]$. The larger the diameters of the discs, the better they behave with respect to cutting, but require greater weight to penetrate the ground and exert greater resistance to rolling $[14,19]$. However, the main function of the cutter disc is to cut the residues, for which a small penetration into the ground is required which, in turn, serves as a counter blade.

To ensure efficient work of the direct seeder, it is important to consider the humidity of the plant material at the time of the sowing operation, since cutting (with discs) is easier when the material is green (just after handling) or well dry. Direct sowing is not recommended a few days after plant cover management, since, in general, the material is still elastic and cutting is more difficult. In addition, the mulch must be dry since if it has recently rained or there is a lot of dew, the straw would be folded into the furrow instead of being cut by the seed discs. In this case, the seed would be deposited on this fold and when the straw was dried again by the sun, it would rise to the surface [20, 21].

Also, there are other commercial components for the handling of residues in the line, such as cleaning wheels and side rollers associated with double discs that are intended to move the cover plants, or residues, from the planting line.

\subsubsection{Opening of furrows:}

The systems that are mainly used in seeders for opening furrows for seeds and fertilizers can be classified into two large groups: discs and shares [14, 17]. For the evaluation of the performance of the furrow opener, the following aspects should be considered: the disturbance or mobilization and the physical properties of the soil resulting in the furrows created; the interaction with residues and the uniformity of the depth of the furrow [22].

The objective of the openers in direct sowing is to minimize the mobilization of the soil and the entry of residues into the furrow, in addition to guaranteeing that the furrow has the most homogeneous shape possible throughout its length. The lower the mobilization of the soil in the furrow, the lower its disaggregation and the consequent transport of particles by erosion.

Reducing the entry of residues into the furrow, eventually displaced by the furrower, is important to avoid "enveloping" the seeds by residues and to ensure better soil-seed contact and the consequent uniformity in germination and emergence. Finally, the maintenance of a furrow with homogeneous shape and depth is essential to guarantee the rapid germination of the seeds and the uniform emergence of the seedlings.

(1) Discs. They can be single or double. In both cases, they are placed slightly inclined with respect to the surface of the ground and the direction of advance.

Simple disc machines do not usually have a front cutter opener element, since the same opening device performs the cutting function. Next to the disk there is a small grid where the seeds or fertilizers are deposited at the bottom of the 
furrow. The edge of the disc can be smooth or ribbed, the latter being more efficient in cutting straw [19].

Double disc seeders open the soil in a "V" shape by the combined action of the two discs. Between them is the drop tube that deposits the seeds or fertilizers at the bottom of the furrow. This system usually requires a cutting disc (triple disc is the name for the association of cutting disc + double disc), and requires more vertical load than the simple disc to reach the same planting depth, so compaction problems can occur in the bottom and on the sides of the planting furrow. Therefore, its use is recommended for soils of medium to sandy texture.

There are different configurations regarding the relative position of the two discs and also the type of cutting edge, the most common being discs with the same diameter paired (side by side) and with a region of contact between them at their edges and below the horizontal line that passes through the center of the discs, and discs of the same diameter but positioned out of phase (out of phase) and with a contact region between them on the edge of the smallest and inside the largest, to reduce input soil and debris between the discs. A common variation of the second configuration has discs of different diameters to obtain a self-cleaning effect since the discs, having different diameters, rotate at different speeds [16]. Double discs are the most common components for direct sowing with reduced spacing between the lines (less than $20 \mathrm{~cm}$ ) and in which there are abundant residues such as rice [23].

In most models of precision direct seeders, the depth of action of the double discs is controlled by means of adjustable side wheels. Simultaneously, the adjustment of the vertical force acting on each line and ensuring the monitoring of the soil surface during operation is done, in most commercial seeders, through individual coil springs. In tight spaces between lines, such as rice, sowing depth control can be done by penetration limiters placed on the outer surface of the discs.

The most common types of flat disc edges (single or double mount) are smooth, wavy, and notched or scalloped [18]. Smooth blades have sharp edges, on one or both sides, which should be kept sharp whenever possible to ensure efficient cutting. The wavy edge has sharp stripes or ripples with different geometries and spaced along and on both sides of the disc. They have a greater cutting capacity than the smooth edge, but it needs more vertical load for penetration and can present more soil adherence on its surface in sticky soils [18]. Notched discs have sharpened and spaced semicircular notches on their periphery in order to improve cutting efficiency and are therefore more suitable for operation on hard soils with a higher amount of residues (Figure 1).

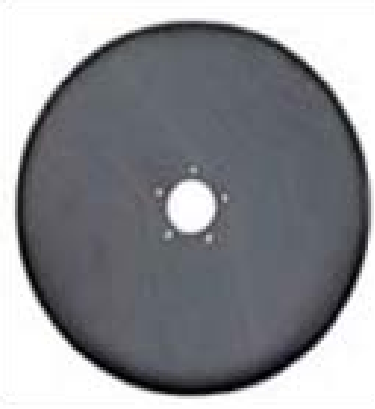

(a)

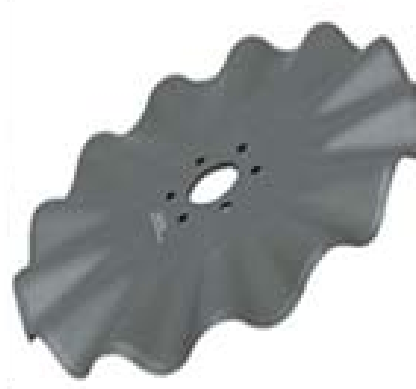

(b)

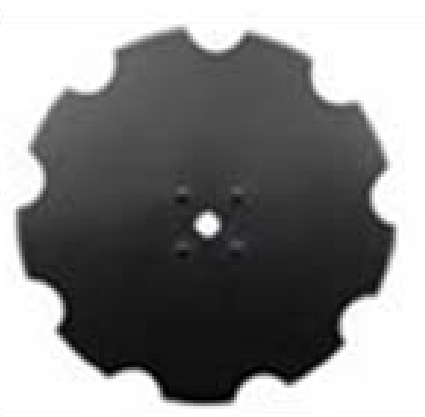

(c)

Figure 1. Flat cutting discs: (a) smooth, (b) wavy and (c) notched (c). Photos: (a) R. Casão; (b) Catalog Recambeos San Martiño sl; (c) Metisa Catalog.

(2) Bars. They exert the mobilization of the soil mainly in the direction of advance (forward) and in the upward direction, which considerably reduces the vertical load necessary to penetrate the soil, when compared to double discs. Their great advantage is the ability to penetrate hard soils (medium to clayey texture) but, on the other hand, they demand more traction force (energy), they present a greater mobilization of the soil and a greater risk of obstruction compared to double discs [22].

The main shares used in direct seeders are the narrow ones of the chisel or hoe types (with "U" profile groove) and inverted "T" profile openers (Figures 2a and 2b). There are different models and geometries in use. Narrow bars are those that have a ratio of depth of operation/width of the screen between 1 and 6 [24] and their importance lies in the lower mobilization of the soil and energy demand [25].

According to [22], the design parameters of the share (angle of attack and width of the chisel tip) and of the operation (depth and working speed) in addition to the soil conditions (texture, moisture content and amount of residue) directly affect the performance of the furrow opener. The authors concluded that increasing the angle of attack, the width of the chisel and the depth of operation increases the degree of soil disturbance and the power requirement. Although the gate with a concave toe cap (Figure 2c) reduces the mobilization of the soil and improves the management of residues in the planting line. 


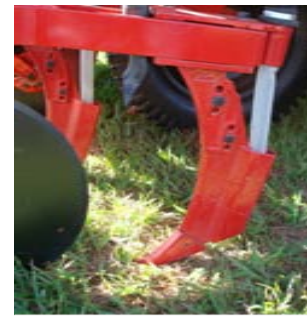

(a)

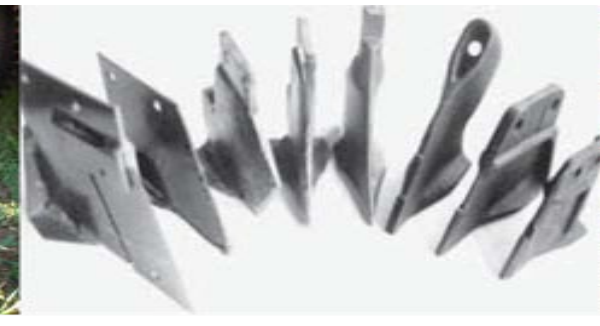

(b)

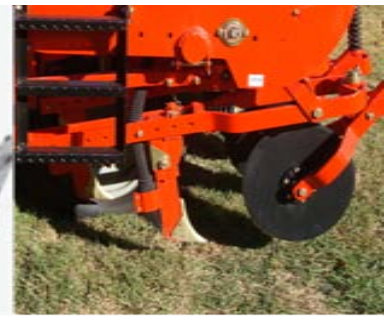

(c)

Figure 2. Shares for direct seeders of the types: (a) chisel; (b) Inverted T; (c) chisel with concave shaped tip. Photos: (ayc) R. Casão; (b) from Baker et al. (2008).

The bars are mounted on arms that are attached to the frame, either by means of articulated quadrilaterals (parallelogram) or by means of an articulated pin. The parallelogram system allows the natural oscillations of the surface to be monitored and the angle of attack constant, which is not the case with the articulated system.

In soils with stones and roots, the use of bars equipped with a trigger device in case of impact is recommended to avoid damage to the tool. The discs are more prone to breakage and blocking of the axes of rotation, due to the constant action of strong impacts, which requires the use of high-resistance materials where there are stones and roots.

Inverted "T" type shares were developed in New Zealand with the aim of overcoming the main problems of type "U" (bars) and "V" (discs) openers and to obtain grooves whose shape had a narrow upper part and a wide base [18]. The initial model consisted of a chisel with lateral wings and slightly inclined in relation to the horizontal. The idea was that the fins could form horizontal "grooves" on both sides of the central groove formed by the chisel, where seeds and fertilizers were deposited on different sides, while keeping the plant cover over the furrow. This model was successful in some soil conditions and in the renovation of pastures, but still has problems when operating with residues on the surface, high wear, poor separation between seeds and fertilizers and requires low operating speed [18].

A later version had a central disc for cutting soil and debris (dual function) and two lateral fins placed on the sides of the disc [18]. The fins cut horizontal slots on each side of the disk where seeds and fertilizers are placed. Behind the fins there are two rubber wheels to cover the grooves and control the depth of sowing and fertilization. According to [18], this model meets all the requirements of a good direct seeding, they work at high speed and the same furrower can be used for precision and continuous flow seeding. Its disadvantages are the higher cost, the energy demand and the vertical load for penetration.

(3) Sowing depth control: The sowing depth is controlled by regulatory mechanisms that must be able to absorb large variations in the reactive forces of the soil on the furrow openers and keep the depth as homogeneous as possible. Springs are the most common vertical penetration regulating mechanisms for seed drills with coulters, taking into account that they are the most economical and do not present major problems. But it is common to find a shallow planting in holes and excessively deep in the elevations of the land, which leads to a poor emergence in both cases.

In the case of double discs, it is common to use springs associated with depth limiting wheels, lateral to the discs. The wheels limit the maximum penetration depth of the discs and the springs keep the assembly (wheels + discs) pressed against the ground surface. This set allows a good control of the sowing depth.

Currently, the sowing units have incorporated parallelograms to make a better copy of the unevenness of the soil and achieve that the sowing body constantly reproduces the relief of the field while maintaining the correct position of attack of the openers, which contributes to better seed placement. Another variant that was added to the detriment of the springs, is that of the pneumatic lungs or hydropneumatic systems so that the load of the seed train is constant in relation to the irregularities of the soil.

\subsubsection{Distribution of seeds and fertilizers:}

An important requirement refers to the dispenser, which must allow, as far as possible, the distribution of seeds of different sizes, geometries and doses for the implementation of crop diversification. In addition to the dosage of seeds, it is especially important to add fertilizer at the same time, placing it in bands, separate from them. Thus, one of the essential functions of direct seeders is that they are capable of simultaneously placing the seed and the fertilizer as close as possible, without them coming into contact [18, 26].

The seed and fertilizer dosing systems used in direct seeders are the same as in conventional systems. In precision sowing stand out, among other principles, the honeycomb seed feeders with mechanical drive and pneumatic, with different configurations, and higher costs. In continuous flow seeding, mechanically driven splined rotors are the most common. There are several commercial models of direct seeders with mechanical drive that allow the use of precision dozers and continuous flow in the same machine, which facilitates the use of cover plants and the mixture of several species, a fundamental aspect in direct seeding as highlighted above. The most common fertilizer dispensers use augers 
and toothed rotors with different configurations. In seeders with a large number of lines, a central tank and pneumatic transport of material are used for each planting line. Recently, technological innovations have been adopted with the aim of increasing the operational capacity and autonomy of direct seeders, such as the adoption of variable rate feeders for seeds and fertilizers [13].

\subsubsection{Coverage and compaction of the furrow.}

The furrow covering and compaction mechanisms perform the functions of uniformly covering the seeds, ensuring the desired sowing depth and providing adequate soil-seed contact to promote their hydration and guarantee the germination process [16]. The two functions are most commonly carried out by dragging loose soil from the edges into the furrow with subsequent soil compression. The optimal level of cover and compaction of the furrow is difficult to determine since it depends on local conditions, especially the type of soil and its humidity, the size of the seed, the type of culture and the rate of evaporation of the soil ( depending on environmental conditions).

As stickiness (more clayey soils) and soil moisture increases, the risk of forming "hard" films on the surface of the seed furrow also increases if the compaction is excessive, which can restrict the emergence of the seeds. Therefore, it is important to reduce the pressure and avoid compaction directly in the furrow the higher the moisture and clay contents of the soil.

However, in soils of medium to sandy texture, it is recommended to apply higher compaction pressures, especially in regions with a high evaporation rate, to reduce the loss of moisture near the seed since the risk of formation of hard surface films is under.

There are several commercial design and material options for the cover and compaction mechanisms of direct seeders, making it easy for the farmer to choose the one that best suits his condition.

Compactor wheels positioned vertically or at an angle to the direction of travel, either single or double, are the main types of mechanisms used.

These wheels are made of both rubber and metal. The rubber ones are semi-flexible which helps to compress the soil in the closure and have the advantage that, in humid or semi-humid conditions and on plastic soils, they detach the adhered earth, which avoids possible accumulations [14].

Simple vertical wheels can have their surface with different geometries (flat, inclined, concave, grooved, grooved, etc.) and widths in order to drag soil into the furrow and exert compaction pressure directly on it. They have a mechanism to adjust the pressure, in general, through springs, as well as the opening angle of the wheels. Single vertical wheels are recommended for medium to sandy soils where the formation of hard surface layers is less likely (Figure 3).

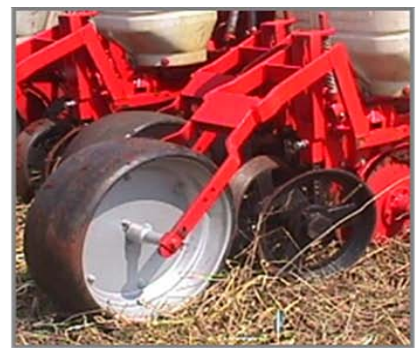

(a)

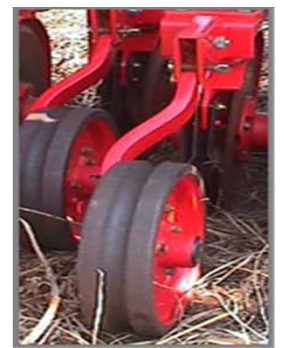

(b)

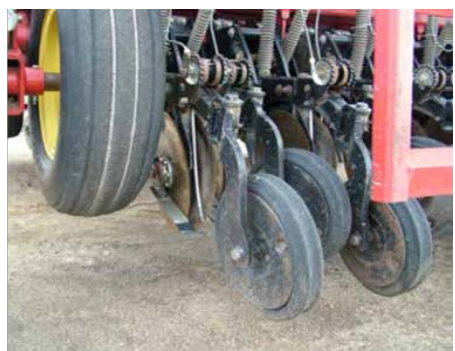

(c)

Figure 3. Simple compactor wheels with different geometries. Photos: (a), (b) R. Casão; (c) Exapta Solutions Inc. Catalog

The double wheels are, in general, inclined for more effective covering action and, like the previous model, they can have different configurations and adjustments, such as being parallel or misaligned (Figure 4). Its main objective is to press the ends and not the center of the furrow surface to improve the soil-seed contact in depth and to leave the soil relatively loose in the seedling emergence region [16]. Narrow double wheels are recommended for medium to clay textured soils.

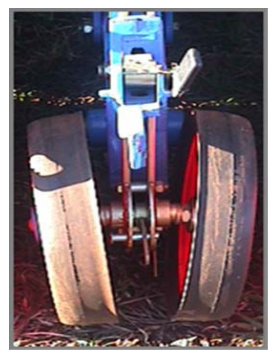

(a)

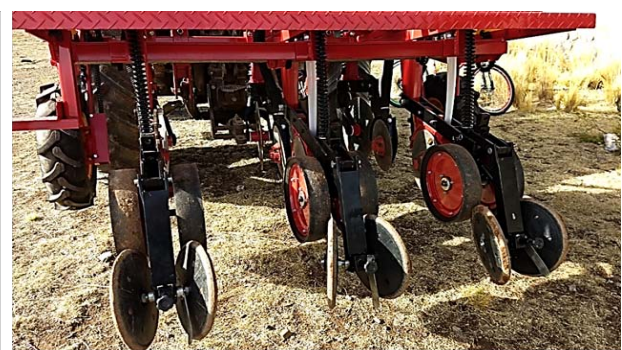

(b)

Figure 4. Wide (a) and narrow (b) double "V” compactor wheels. Photos: (a) R. Casão; (b) A. Araújo. 
In addition, accessories have been added to press the seeds into the bottom of the furrow (seed signers), before closing, which guarantees greater uniformity of the sowing depth, with the grain treading reed kit (Figure 5) being the most widespread [25].
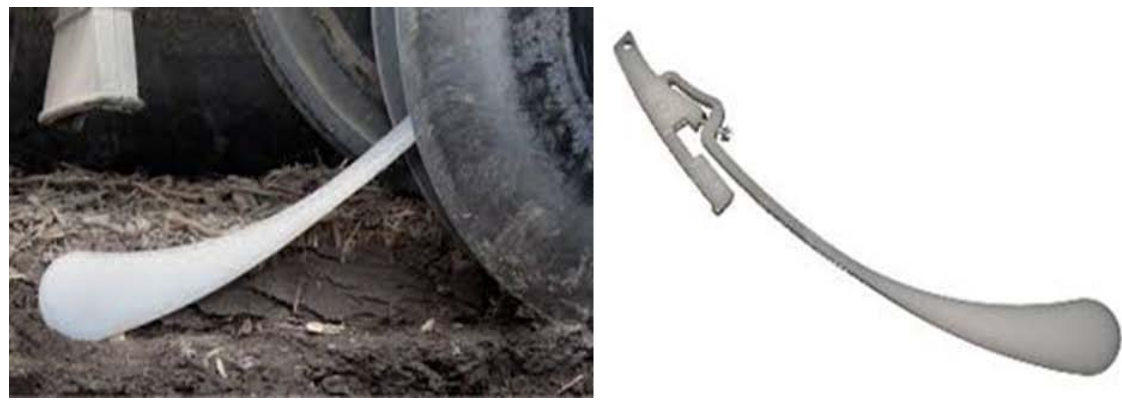

Figure 5. Seed signing for direct sowing. Photos: Keaton Seed Firmers Catalog.

Other innovations on the market aim to improve the quality of the furrow finish in direct sowing, especially in conditions of compacted soil or with high humidity, when only the action of the common wheels does not achieve good results. Paired finger wheels, arranged in front of the compaction wheels or in combination with them (side by side), have been spread to improve coverage and closure by breaking the side walls of the groove at compacted soils or with a strong presence of roots (Figure 6).

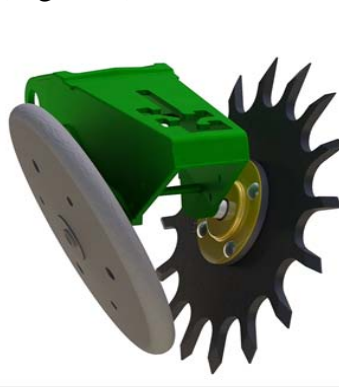

(a)

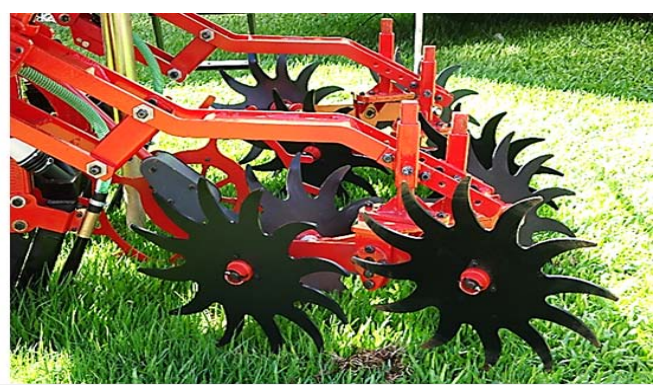

(b)

Figure 6. Finger wheels associated with compactor wheels (a) and in pairs (b) Photos: (a) Martin Industries Catalog, (b) A. Araújo.

\subsubsection{Direct seeder power requirements.}

Seeders with jet (or continuous flow) disk dispensers have weights that vary from 700 to $900 \mathrm{~kg} / \mathrm{m}$ of working width for single-disk ones, increasing to $1,000-1,300 \mathrm{~kg} / \mathrm{m}$ for double-disk ones. The minimum tractor power for the former is of the order of $27 \mathrm{HP} / \mathrm{m}$, while the others need 34 to $40 \mathrm{HP} / \mathrm{m}[14,28]$.

On the other hand, according to [17] considering a traction efficiency of $65 \%$, the required motor power varies from 4 to $15 \mathrm{HP}$ per opener, which depends on the type of soil, density, the state of decomposition of the roots, the design of the openers, the weight of the machine and the sowing speed [28].

In general, direct seeders are heavier and more robust than conventional ones, so the tractors that tow them must have, at least, around $120 \mathrm{HP}$ of power in their engine, although machines with more than $4 \mathrm{~m}$ working width or pneumatic seeders will surely have more demand. This requirement is not usually due to the force required by the traction but to the weight of the planter, which can create stability problems on slopes and turns, especially on suspended machines [14].

\subsubsection{Other important features of direct seeders}

The functions that a direct seeder must fulfill were described and are mainly related to the mechanisms of soil-machine interaction. But, there are also other important characteristics that require analysis in the process of selecting the most appropriate direct seeder for a specific situation [18].

$>$ Working width: It depends on the availability of power, the topography of the land, the amount of inputs that are taken to the field and their transport. However, it is closely related to the design of the machine: size of the mechanisms, space in the toolbars for installation of the assemblies, spatial overlapping of the parts, etc. For rice cultivation it is recommended to be less than six meters when working on level ground and $4.5 \mathrm{~m}$ for unlevel soils.

$>$ Ability to copy the micro-reliefs of the soil surface: They must be able to copy the irregularities present in the ground (dikes or taipas), with small changes in the depth of planting and fertilization. Each opener must rise and 
fall in response to surface irregularities, independent of the other openers and maintaining its relative ground attack position.

$>$ Mechanisms Penetration Capability: For a planter to operate properly, its weight or penetration component must be sufficient to provide the combined penetration loads of all of its openers when operating in the most difficult conditions. The racks must be on wheels to avoid bumps on uneven terrain.

$>$ Rolling: To reduce soil compaction, it is advisable to use seeders with high flotation tires.

$>$ Transport Considerations: Rear wheel designs, positioned at both rear ends of the planter frame, are suitable for planters up to six meters wide and have the advantage of reducing lateral forces during turns and allowing two or more machines work together.

> Utilization of available power. In direct sowing, the traction capacity of a tractor is as important as the available power of the engine, which is why four-wheel drive tractors are useful. Tractors that work close to the traction limit will cause more loose soil (wheel slip), and therefore, greater differences in opener behavior between those that are in or out of the area of the wheel tracks. On the other hand, the ability to make tight turns of the seeder-tractor aggregation is required.

$>$ Storage and dosage of products. Vertical plate sowing mechanisms are faster and less sensitive to seed shape than horizontal sowing plates, although they are more expensive [18].

> The planter should also be able to operate with adjustable row spacing and as much flexibility as possible to allow the cultivation of different species of cover and rental plants. The transverse misalignment between the components of the planting lines is essential to reduce the risk of obstruction by residues, especially with a greater volume of soil coverage.

Globally, a wide variety of no-tillage drills are available for two- and four-wheel tractors, from small $15 \mathrm{HP}$ to large $400 \mathrm{HP}$ tractors. Among those that operate with double disc openers, versions with offset discs of different diameters are particularly popular in Brazil, which are suitable for smaller tractors, as they can cut vegetable residues in reasonable volumes on medium textured soils with the weight of the own equipment (less than $100 \mathrm{~kg}$ / line), while other double disc planters, often under more rigorous conditions, require weights of 150 to $250 \mathrm{~kg}$ / line or more. However, for many developing countries double disc planters are prohibitively expensive due to the cost of high-grade steel for the discs and the additional weight [9].

On the other hand, chisel-type no-till seeders, such as those actually preferred in India and China as low-cost equipment for small-sized tractors, have serious limitations in handling residues, particularly when sowing fine grains over residues heavy corn, wheat or rice. Although, in China and India to solve these problems, the power of the PTO is used for tillage with rotary discs or coulters or picking up the debris in front of the furrow opener with a strip cutter and blowing on the row planted behind the team, known commercially as "Happy Seeder" [9].

\subsection{Direct seeders used in rice growing areas}

A number of low soil disturbance seeders have been developed in South and Southeast Asia for small two-wheel tractors as it is an attractive option for AC-based small farm mechanization. Often the challenge in this region is to design a multi-function planter capable of sowing with minimal soil disturbance, adapting to many types of crops, and operating on large amounts of residues on the surface which is common in areas of rice and wheat.

In Bangladesh, the Versatile Multi-Crop Planter (VMP) was designed for small farms and operation with 12-16 horsepower two-wheel tractors [29]. The equipment has milling organs (rotating C-shaped coulters) located in front of the furrow openers to open the furrow and clean the straw from the surface, which can be changed quickly for different seeding systems (strip, shallow tillage, zero tillage or in beds), sowing methods (trickle or precision), seed and fertilizer rates, row spacing, seed size and planting depths. The VMP planter allows control of soil disturbance to strips with adjustable widths and depths, and for low soil moisture conditions, an optional set of bars can be used to ensure deeper seed placement [30]. Research results in Bangladesh show that soil organic carbon content, grain yield and fuel consumption have improved in strip cropping systems compared to conventional and ridged systems. The strip seeding system using VMP is the best option to manage residues and can handle up to $5.5 \mathrm{t} / \mathrm{ha}$ of rice or wheat residues [30, 31].

Bangladesh has also developed the transplantation of rice seedlings without waterlogging the soil, by means of strip planting using VMP. Under this technique, a single pass is made with VMP, leaving between 60 and $70 \%$ of the soil surface unmobilized, followed by the application of irrigation water and 24 hours later the seedlings are transplanted, either mechanized or manually. This technique made possible the adoption of conservationist practices in the cultivation of flooded rice and the results show that the grain yield in strip planting is similar or superior to that of conventional mud systems [30, 31].

In eastern Asia, China is the country where conservation agriculture is most developed and adoption has been very rapid in recent years. The country has AC machinery factories ranging from manual direct seeders, direct seeders for two-wheel tractors and direct seeders of medium and small size for four-wheel tractors. As the handling of rice and wheat crop residues during direct seeding is a major concern in China, direct seeders often include passive or active 
residue management devices [32].

The ARC Gongli planter model for two-wheel tractors is manufactured in China and its design is based on the ACIAR Rogro developed in Australia. It is a multi-crop planter with variable line spacing and up to four coulters that can be adjusted along the bars. Seed and fertilizer tanks are mounted above and on both sides of the tractor control levers to ensure good visibility of the operation [32]. Single (fertilizer) and double (seed) adjustable grooved roller feeders allow you to meter seeds of various sizes and dispense fertilizers at variable rates [13]. This model has been evaluated behind the rotating blades of a rotary tiller to improve its seeding performance on rice and wheat residues. Other models available in China and India use rotating organs in front of each line to handle debris and reduce soil disturbance [32].

In China, four-wheel tractor drills with passive residue handling devices generally operate with three or more lines and have two or more tool bars to reduce clogging and improve residue flow, plus they have greater ground clearance to increase space free and opens narrow and misaligned furrows. If there is space between the sowing lines, complementary passive devices can be used such as single or double discs with tips, which rotate when in contact with the soil surface, and vertical rollers with free movement both in front of the furrow openers [32].

The seeders for four-wheel tractors with active anti-blocking debris devices are actuated by the take-off of rotating blades to cut the soil or to chop debris in front of the furrow openers.

One direct seeder model that is becoming popular in India and China, as well as other Asian countries, is the Happy Seeder. This planter combines the functions of waste management and seeding in the same machine. The handling device is composed of free-moving oscillating blades, near each inverted T-type furrow opener, which cuts, lifts and distributes the standing residue and loose straw, over the sown area behind the planter, which sows in bare soil [33]. A later modification increased the rotational speed of the blade shaft, known as the Turbo Happy Seeder. In China, a rear rotary axle was added for cleaning between lines for operation under high amounts of waste [32]

\subsection{Technological trends}

As no-till systems develop and optimize over time, the trend is clearly towards minimally disturbed row openers such as double disc tools [9].

Currently, new designs of seeders are being validated that allow the planting of rice with distances ranging from 13 $\mathrm{cm}$ to $21 \mathrm{~cm}$. Using an articulated triple pivot system, with special pneumatic lungs, with a load of 40 bars, which maintains constant pressure on each active organ of the sowing body, being able to perfectly copy the irregularities present in the rice field. In addition, with the possibility of being used in wheat, pastures and even for corn.

In China, a series of machines have been developed with different variants of both mechanical and pneumatic sowing that adjust to the most dissimilar situations (sowing scale, sowing and fertilization method, power of tractors, 2 and 4-wheel tractors) and schemes sowing [34].

According to [27] the seeders that the market will seek in the coming years will be increasingly specific, possibly with a kinematic train that the distributors move electrically guided by intelligent operating software. The sowing bodies will continue to be equipped with cutting and removal elements, which will be increasingly specific for each type of soil and will be suitable for placing stubble sweepers. With design of springs with sensors of height of the chassis with respect to the ground that regulate of automatic form the seeder, responding automatically to the uniformity of penetration that the ground and the stubble require.

The sowing trains will be assisted by hydropneumatic shock absorbers, pneumatic lungs plus shock absorber, or hydraulic cylinders with hydrogen lungs and intelligent load regulation by means of copying wheels with dynamic load measurement sensors. On the other hand, there are already new sensors placed in the sowing train of the machines that provide information on organic matter, furrow cleaning, air chamber, temperature, soil humidity, temperature and cation exchange capacity. Information that makes it possible to automatically manage the individual sowing density per sowing body with a reaction capacity of less than $2 \mathrm{~m}$, which makes it possible to establish variable sowing densities within a field, with a precision of up to $1 \mathrm{~m}^{2}[27,35]$.

In addition, it is expected that the future will be marked by precision agriculture, with a high percentage of tractors with "automatic pilots" and even the emergence of agricultural robots, which allows automating direct seeding and increasing the efficiency of the process [36].

\subsection{Conclusions and important points about the design of direct seeders for rice in Cuba}

The experiences obtained worldwide on the adoption and diffusion of CA show the possibility of adapting some seeders initially conceived for sowing in soft soils, which could be a first step to follow in Cuba and other countries for the transition to a conservation agriculture based on direct seeding and be successful in rice agroecosystems [37, 38, 39, 40]. In this sense, the evolutionary dynamics of seeders for direct sowing and the consolidated knowledge in Brazil [23] indicate that in the process of adaptation or acquisition of a seeder for direct sowing in rice agroecosystems, the following should be taken into account technical principles: 
- Use of a double disengaged disc system for crops with reduced spacing between the sowing lines (less than 20 $\mathrm{cm})$;

- Use of a system, with cutting disc, grating and double disc for sowing crops with spacings between lines greater than $30 \mathrm{~cm}$, mainly in clay-textured soils;

- Adoption of mismatched double discs, taking into account that, within the various commercial models available, the assemblies that tend to have the best performance (lower energy demand and less soil stirring) are those whose joint angle is small $\left(<8^{\circ}\right)$ and whose minimum phase shift is greater than $25 \mathrm{~mm}$;

- Reduced thickness bars (less than $25 \mathrm{~mm}$ ) and with an angle of attack of 20 to $25^{\circ}$ in relation to the ground surface, result in reduced movement of the ground and in less traction and penetration effort;

- For better performance in terms of breaking the soil, apart from considering the geometry of the elements that break the soil, the arrangement and arrangement of these under the planter must be taken into account. In this sense, the element that breaks the soil must have a wide vertical fluctuation, independent and with the most uniform load possible, to adequately accompany the micro-reliefs of the soil surface;

- Using parallelograms for mounting and fixing the elements that break the ground (commonly called pantographs) keep their angles of attack to the ground practically unaltered;

- The performance of the planter, in terms of breaking the soil, will be better the greater the independence between its breaking elements, both in the line and between the sowing lines;

- $\quad$ Regarding the flow of the straw under the planter, two aspects are important: the height of the chassis in relation to the surface of the ground (free space) and the offset between the elements of two neighboring lines that break the ground;

- The "free space", normally, is related to the geometry of the elements to break the ground and its fixation. The use of discs, as breaking elements, with diameters less than $40 \mathrm{~cm}$, have greater difficulty to supplant, without clogging, high amounts of stubble (greater than $10 \mathrm{t} / \mathrm{ha}$ );

- The flow of the straw under the planter will be better the greater the phase shift between the elements that break the soil. East offset, both in the longitudinal direction and in the transverse direction between the sowing lines;

- Devices that allow the most continuous regulation of the spacing between the lines are desirable in a planter.

- To facilitate movement on narrow roads, it is advisable to (optionally) fit mechanical wheels for longitudinal transport.

\section{Authors' contribution}

All the authors contributed equally. They read the final version, and approved it for the publication.

\section{References}

[1] Piedra, C. L., Ramírez, M. F., Luna, M. S., and Araya, V. A. (2017). Manual of good agricultural and environmental practices for rice cultivation in the Barra del Colorado National Wildlife Refuge (RNVS Barra de Colorado), Costa Rica, p. 17. Available fom: https://www.sinac.go.cr.

[2] Franques, J. M. (2018). The new dry sowing system for rice. Firstedition. Spain: Community of Regants-Sindicat Agrícola de l'Ebre, p. 58. ISBN: 978-84-697-5393-4.

[3] Nandana, R., Singha, V., Shankar, S., Kumarc, V., Krishna, K., Prasad, C., Pooniad, S., Kanwar, R., Bhattacharyyae, R., and McDonaldf, A. (2019). Impact of conservation tillage in rice-based cropping systems on soil aggregation, carbon pools and nutrients. Geoderma, 340: 104-114. doi.org/10.1016/j.geoderma.2019.01.001.

[4] Iqbal, A., He, L., Khan, A., Wei, S., Akhtar, K., Ali, I., Ullah, S., Munsif, F., Zhao, Q., and Jiang, L. (2019). Organic Manure Coupled with Inorganic Fertilizer: An Approach for the Sustainable Production of Rice by Improving Soil Properties and Nitrogen Use Efficiency. Agronomy, 9, 651. doi: 10.3390/agronomy9100651.

[5] Domínguez, C., Díaz, G., Domínguez, D., Miranda, A., Duarte, C., Ruiz, M., Rodríguez, A., and Martin, R. (2020). Influence of Conservation Agriculture on soil properties under irrigated rice cultivation. Agricultural Technical Sciences Magazine, 29(3): 75-83, 2020. ISSN: 1010-2760.

[6] Grohs, M. (2018). Post-colheite management and coverplants: Influence on nutrient cycling, greenhouse effect gas emissions and rice production. [Tese of doutorado]. [Brazil]: Federal University of Santa Maria, p. 91.

[7] Song, K., Zheng, X., Weiguang, L. V., Qin, Q., Sun, L., Zhang, H., and Xue, Y. (2019). Effects of tillage and straw return on water-stable aggregates, carbon stabilization and crop yield in an estuarine alluvial soil. Scientific Reports, 9: 4586. doi.org/10.1038/s41598-019-40908-9.

[8] Issaka, F., Zhang, Z., Betancourt, Y., Zhao, Z., Amézquita, E., Sheka Kanu, A. B., Li, W., and Acquatella J. (2019). Zero Tillage Improves Soil Properties, Reduces Nitrogen Loss and Increases Productivity in a Rice Farmland in Ghana. Agronomy, 9(10): 641, ISSN: 2073-4395. doi: 10.3390/agronomy9100641.

[9] Friedrich, T., Kienzle, J., and Kassam, A. (2014). Conservation Agriculture in Developing Countries: The Role of Mechaniza- 
tion. Research Gate, FAO, Rome, Italy. Available from: https://www.researchgate.net/publication/260387802.

[10] Kassam, A., Friedrich, T., and Derpsch, R. (2018). Global spread of Conservation Agriculture. International Journal of Environmental Studies. doi.org/10.1080/00207233.2018.1494927.

[11] Farooq, M., Siddique, K. H. M., Rehman, H., Aziz, T., Lee, D. J., and Wahid, A. (2011). Rice direct seeding: experiences, challenges and opportunities. Soil and Tillage Research, 111(2): 87-98. doi.org/10.1016/j.still.2010.10.008.

[12] Javier, P. J., Bragachini, M., and Casini, C. (2011). Direct Sowing. Technical Update No. 58-February. Editions National Institute of Agricultural Technology "INTA", Argentina. P. 28. Available from: www.cosechaypostcosecha.org.

[13] Araújo, A. G., Sims, B., Desbiolles, J., Bolonhezi, D., Haque, E., Jin, H., et al. (2020). The status of mechanization in Conservation Agriculture systems. In: Kassam, A. (Ed.), Advances in Conservation Agriculture Volume 1-Systems and Science. Burleigh Dodds Science Publishing Limited, Cambridge, UK. 2019. ISBN-13: 9781786762641.

[14] Gil, J. A. and Veroz, Ó. (2009). Saving and Energy Efficiency with Conservation Agriculture. Editorial Fund of the Institute for Energy Diversification and Saving (IDEA). P. 52. ISBN: 978-84-96680-44-9. Available from: www.idae.es.

[15] Desbiolles, J. (2005). Mechanics and Features of Disc Openers in Zero-Till Applications. Research paper, p. 6, Agricultural Machinery Research and Design Centre (AMRDC), University of South Australia, Mawson Lakes. Available from http://www.unisa.edu.au/amrdc/Areas/Proj/SeedTrials/Waikerie_field_day_disc.

[16] Ashworth, M., Desbiolles, J., and Tola, E. K. (2010). Disc Seeding in Zero-till Farming Systems—A Review of Technology and Paddock Issues. Western Australian No-Tillage Farmers’ Association (WANTFA), Northam, Australia.

[17] Munir, M. A., Iqbal, M., Munir, A., Ahmad, M., and Miran, S. (2012). Evaluation of three seed furrow openers mounted on a zone disk tiller drill for residue management, soil physical properties and crop parameters. Pak. J. Agri. Sci., 49(3): 315-321. ISSN (Online) 2076-0906. Available fom: http://www.pakjas.com.pk.

[18] Baker, C. J., Saxton, K. E., Ritchie, W. R., Chamen, W. C. T., Reicosky, D. C, Ribeiro, M. F. S., et al. (2008). No-tillage sowing in conservation agriculture. Food and Agriculture Organization of the United Nations. Editorial Acribia, SA Zaragoza (Spain). P. 381. Available from: www.editorialacribia.com. 2008.

[19] García, S., Serwatowski, R., Cabrera, J. M., Saldaña, N., Flores, A., and Gutiérrez, C. (2012). Analysis of the performance of four models of straw cutters used in seeders for direct sowing. Mexican Journal of Agricultural Sciences, 3 (spe 4): ISSN 2007-0934. Available fom: www.scielo.org.mx/scielo.php?script=sci_arttext\&pid=S2007-09342012000900004.

[20] Haque, M. E., Bell, R. W., Jahiruddin, M., Hossain, M. M., et al. (2018). Manual for Smallholders’ Conservation Agriculture in Rice-based Systems. Murdoch University. P. 108. Available from: http://researchrepository.murdoch.edu.au/id/eprint/41693.

[21] Tullberg, J. N., Dixon, J., and Kearns, S. (2010). Conservation agriculture in Australia. Available from: www.mapama.gob.es.

[22] Aikins, K. A., Antille, D. L., Jensen, T. A., Barr, J. B., Ucgul, M., and Desbiolles, J. M. A. (2018). No-tillage tine furrow opener performance: soil-tool-residue interactions, tool geometry and settings. ASABE Paper No.: 1800251. St. Joseph, MI.: ASABE. doi: 10.13031/aim.201800251.

[23] Sattler, A. (2006). Seeders for direct sowing. Technological Evolution and Problems in the Machine/Soil relationship in southern Brazil. In thebook: Contributions of Science and Technology to the Productive and Sustainable Management of the Soils of the Southern Cone, Chapter: II Relationship Seeder-soil in Direct Sowing: "Problems and Solutions”, Uruguay, pp. 269-272. ISBN 92-90-39-751-9.

[24] Godwin, R. J. and O’Dogherty, M. J. (2007). Integrated soil tillage force prediction models. J. Terrramech, 44(1): 3-14. doi.org/10.1016/j.jterra.2006.01.001.

[25] Conte, O., Levien, R., Debiasi, H., Sturmer, S. L. K., Mazurana, M., and Muller, J. (2011). Soil disturbance index as an indicator of seed drill efficiency in no-tillage agrosystems. Soil and Tillage Research, 2011, 114(1): 37-42. doi: 10.1016/j.still.2011.03.007.

[26] Fick, C. (2000). On the money. Farm Journal, April, pp. 12-13.

[27] Bragachini, M., Sánchez, F., Urrets, G., Scaramuzza, F., Villarroel, D., and Vélez, J. P. (2018). Complete report of the seed drills category. INTA Manfredi. Argentina. Available from: TodoAgro.com.ar.

[28] Yezekyan, T., Marinello, F., Armentano, G., and Sartori, L. (2018). Analysis of cost and performances of agricultural machinery: Reference model for sprayers. Agron. Res., 16, 604-614.

[29] Bell, R. W., Haque, E., Jahiruddin, M., Rahman, Md. M., et al. (2019). Conservation Agriculture for Rice-Based Intensive Cropping by Smallholders in the Eastern Gangetic Plain, Agriculture, 9, 5. doi: 10.3390/agriculture9010005.

[30] Haque, M. E., Bell, R.W., Jahiruddin, M., Vance, W., Islam, M. A., and Salahin N. (2014). Residue Handling Capacity of the Versatile Multi-crop Planter for Two-wheel Tractors. In: Proceedings of the Conference on Conservation Agriculture for Smallholders in Asia and Africa. 7-11 December 2014, Mymensingh, Bangladesh. (Eds. WH Vance, RW Bell, ME Haque). Pp. 13-14.

[31] Mobarak, M., Begumb, M., Hashemc, A., Rahmanb, M., and Belld, R. W. (2021). Mulching and weed management effects on the performance of rice (oryza sativa 1.) transplanted in non-puddled soil. Journal of Wastes and Biomass Management, 3(1), 3-21. doi.org/10.26480/jwbm.01.2021.13.21. 
[32] He, J., Zhang, Z. Q., Li, H. W., and Wang, Q. J. (2014). Development of small/medium size no-till and minimum-till seeders in Asia: a review. International Journal of Agricultural and Biological Engineering, 7(4), 1-12. doi: 10.3965/j.ijabe.20140704.001.

[33] Sidhu, H. S., Manpreet, A., Humphreys, A. E., Yadvinder, B. C. F., et al. (2007). The Happy Seeder enables direct drilling of wheat into rice stubble. Australian Journal of Experimental Agriculture, 47, 844-854. Available from: www.publish.csiro.au/journals/ajea.

[34] Zhang, M. H., Wang, Z. M., Luo, X. W., Zang, Y., Yang, W. W., Xing, H., et al. (2018). Review of precision rice hill-drop drilling technology and machine for paddy. Int J Agric \& Biol Eng., 11(3): 1-11. Available from: https://www.ijabe.org.

[35] Desbiolles, J., Saunders, C., Barr, J., Riethmuller, G., Northover, G., Tullberg, J., and Antille, D. (2019). Machinery Evolution for Conservation Agriculture. In J. Pratley and J. Kirkegaard (Eds.), “Australian Agriculture in 2020: From Conservation to Automation” pp. 81-106 (Agronomy Australia and Charles Sturt University: Wagga Wagga). ISBN-13: 978-0-6485819-0-1. http://www.csu.edu.au/research/grahamcentre.

[36] Santos, S. and Kienzle, J. (2020). Agriculture 4.0-Agricultural robotics and automated equipment for sustainable crop production. Integrated Crop Management, Vol. 24. Rome, FAO. ISSN 1020-4555.

[37] Miranda, A. (2020). Impact of mechanized rice transplant technology. Cuban Journal of Public and Business Administration. September-December 2020; IV (3): 334-349 [Consulted 20 February 2021] Available at: https://apye.esceg.cu/index.php/apye/article/view/143.

[38] Paneque, P., Fernández, C., Miranda, A., Morejón, Y., anad Gómez, V. (2019). Current situation of agricultural mechanization and conservation agriculture in Latin America. AMA, Agricultural Mechanization in Asia, Africa and Latin America, 2019, Vol. 50, No. 2, pp. 13-19. ref.35. ISSN : 0084-5841.

[39] Miranda, A., Paneque, P., Abraham, N., and Suárez, M. (2009). Comparativeanalysis of the total energycosts, exploitation and fuel consumption of rice cultivation in dry technologies and direct flooding. Agricultural Technical Sciences Magazine, 2009, 18(3): 70-75. Recuperado de: https://www.redalyc.org/articulo.oa?id=93215944013.

[40] Paneque, P., Miranda, A., Abraham, N., and Suárez, M. (2009). Determination of energy and operatingcosts of the dry rice cultivation system. Agricultural Technical Sciences Magazine, 2009, 18(1): 7-10. [consulted 20 January 2020] Available in: http://www.redalyc.org/articulo.oa?id=93215240002. 